\title{
Article \\ Unmanned Aerial Vehicles Rescue System Design and Traffic Model Planning
}

\author{
Haoran Zhao ${ }^{1}$, Wenjie Yang ${ }^{2}$ and Huibin Zhu ${ }^{1, *}$ \\ 1 Faculty of Modern Agricultural Engineering, Kunming University of Science and Technology, \\ Kunming 650500, China; zhaohaoran@stu.kust.edu.cn \\ 2 School of Mathematics and Data Science, Shaanxi University of Science and Technology, Xi'an 710021, China; \\ yangwenjie@sust.edu.cn \\ * Correspondence: hbzhu113@kust.edu.cn
}

check for

updates

Citation: Zhao, H.; Yang, W.; Zhu, H Unmanned Aerial Vehicles Rescue System Design and Traffic Model Planning. Appl. Sci. 2021, 11, 10481. https://doi.org/10.3390/app112110481

Academic Editor: Tetsuya Hiraishi

Received: 10 October 2021

Accepted: 4 November 2021

Published: 8 November 2021

Publisher's Note: MDPI stays neutral with regard to jurisdictional claims in published maps and institutional affiliations.

Copyright: (c) 2021 by the authors. Licensee MDPI, Basel, Switzerland. This article is an open access article distributed under the terms and conditions of the Creative Commons Attribution (CC BY) license (https:/ / creativecommons.org/licenses/by/ $4.0 /)$.

\begin{abstract}
Unmanned Aerial Vehicles (UAV) are widely used in disaster relief and road exploration in recent years. This paper mainly studied the emergency response of UAVs after disasters. The UAV response system is mainly suitable for the distribution of necessities and road exploration after geological disasters and tsunamis in coastal areas. By analyzing the problem and making reasonable assumptions, the optimization model was established with the traffic planning theory, and MATLAB software was used to program and solve the problem. An optimal scheduling scheme was presented to solve these problems. The normalization method was used to select a highly capable UAV. Taking the minimum volume of idle space buffer material as the objective function and taking into account the constraints, such as payload of unmanned aerial vehicle, a single objective programming model was established. The results are as follows: Each International Standards Organization (ISO) cargo container has five UAVs B, one UAV C, one UAV F and one UAV H. It provides 188 days of relief requirements with ISO cargo containers' space utilization of $71.4 \%$. The research shows that the UAV response system has the functions of necessities distribution and road exploration after disasters, and can be used to deal with the emergency response after disasters in coastal areas, and has a wide range of applicability.
\end{abstract}

Keywords: transportation planning; optimal design; normalization method; single-target planning model

\section{Introduction}

How to develop a timely and efficient disaster relief program has been widely studied. With the acceleration of global warming, more and more people are affected by worsening tsunamis and hurricanes [1,2]. Earthquakes and other geological disasters also bring endless disasters to human beings [3-5]. The storm, with fierce winds and heavy rain, knocked down utility poles and almost all transmission lines [6]. In recent years, human beings have carried out a lot of research on tsunami warnings [7-9], and put forward some solutions to the problem of disaster relief $[10,11]$.

In order to respond to the emergency response after a disaster, many emergency disaster relief systems have been designed. Serhan et al. [12] and German A et al. [13] achieve an emergency response by prepositioning disaster relief supplies. A certain amount of emergency supplies were stored in specific locations to respond to disasters. Linet [14] and Yoshinori et al. [15] used helicopters to transport relief supplies by planning specific routes. A large number of materials were transported by helicopter clusters, which eases material demand. Deng et al. [16] used bionic robots to handle emergency response problems. However, some of these methods have higher requirements for the surrounding environment, and some have not solved the transportation problems of emergency materials, especially pharmaceuticals. 
To address the emergency response after a disaster, an unmanned aerial vehicle rescue system was planned and designed. The system should have road reconnaissance and emergency drug distribution functions and be able to deploy quickly.

It is necessary to develop a reasonable disaster response system model [17]. The key to UAV disaster relief is the configuration of items and the planning of routes. In this respect, many people had done some research, for example, Villaseñor et al. [18] presented an ellipsoidal mapping algorithm (EMA) that was designed using covariance ellipsoids and clustering algorithms. Goodrich et al. [19] presented a brief analysis of the WiSAR problem with an emphasis on practical aspects of visual-based aerial search. Zhou et al. [20] proposed an air-based collaborative vehicle network architecture. Giordan et al. [21] studied monitoring methods and techniques for unmanned aerial vehicles in engineering geology applications. Casella et al. [22] presented recent progress in beach surveys and their respective measurements in UAV and photogrammetry. Alzenad et al. [23] proposed an optimal placement algorithm for UAV base stations, which maximizes the number of users covered with the minimum transmit power. However, the above research does not involve how to configure a complete disaster response system and the goods distribution of UAVs.

Therefore, this paper mainly solves the configuration of disaster response systems and the path planning of UAVs with load.

\section{Materials and Methods}

\subsection{Selection of $U A V$}

Among various types and brands of UAVs, eight UAVs meeting the requirements were selected according to their overall dimensions, payload capacity and configuration functions. The potential candidate UAVs considered by UAV formation are shown in Table 1.

Table 1. UAV configuration of each size.

\begin{tabular}{cccccccccc}
\hline & \multicolumn{2}{c}{ Shipping Container Dimensions } & \multicolumn{2}{c}{ Performance Characteristics/Capabilities } & \multicolumn{2}{c}{ Configurations Capabilities } \\
\hline Drone & $\begin{array}{c}\text { Length } \\
\text { (in.) }\end{array}$ & $\begin{array}{c}\text { Width } \\
\text { (in.) }\end{array}$ & $\begin{array}{c}\text { Height } \\
\text { (in.) }\end{array}$ & $\begin{array}{c}\text { Max Payload } \\
\text { Capability } \\
\text { (lbs.) }\end{array}$ & $\begin{array}{c}\text { Speed } \\
\text { (km/h) }\end{array}$ & $\begin{array}{c}\text { Flight Time } \\
\text { No Cargo } \\
\text { (min) }\end{array}$ & $\begin{array}{c}\text { Video } \\
\text { Capable }\end{array}$ & $\begin{array}{c}\text { Medical } \\
\text { Package } \\
\text { Capable }\end{array}$ & $\begin{array}{c}\text { Drone Cargo } \\
\text { Bay Type* }\end{array}$ \\
\hline A & 45 & 45 & 25 & 3.5 & 40 & 35 & Y & Y & 1 \\
B & 30 & 30 & 22 & 8 & 79 & 40 & Y & Y \\
C & 60 & 50 & 30 & 14 & 64 & 35 & Y & Y \\
D & 25 & 20 & 25 & 11 & 60 & 18 & Y & Y \\
E & 25 & 20 & 27 & 15 & 60 & 15 & Y & 2 \\
F & 40 & 40 & 25 & 22 & 79 & 24 & Y & Y \\
G & 32 & 32 & 17 & 20 & 64 & 16 & N & N \\
H & 65 & 75 & 41 & N/A & N/A & Indefinite & N & N/A \\
Tethered & & & & & & & & &
\end{tabular}

In order to select a UAV with excellent comprehensive performance (called strong UAV), the performance characteristics of different UAVs were comprehensively evaluated by the normalization method [24], and these characteristics were defined as service capability.

The ideal flight distance is equal to the average speed times the time of no cargo flight. Using this formula, the ideal flight distance of various types of UAVs can be calculated.

$$
s_{0}=\bar{v} \times t_{0},
$$

where $s_{0}$ is the flight distance of $\mathrm{UAV}, v$ is the average flight speed of $\mathrm{UAV}$, and $t_{0}$ is the flight time of UAV. 
The ideal flight distance and the maximum payload are normalized, respectively, to calculate the service capability of different UAVs. The normalized results are shown in Table 2.

$$
\begin{gathered}
s_{0 i}^{*}=\frac{s_{0 i}-s_{0 \min }}{s_{0 \max }-s_{0 \min }} \\
w_{i}^{*}=\frac{w_{i}-w_{\min }}{w_{\max }-w_{\min }} \\
z=v_{i}^{*} \times s_{0 i}^{*}
\end{gathered}
$$

where $s$ is the flight distance of the UAV, $w$ is the maximum payload capability of the UAV,

\begin{tabular}{|c|c|c|c|c|c|c|c|}
\hline \multirow[b]{2}{*}{ UAV } & \multicolumn{4}{|c|}{ Performance Characteristics/Capabilities } & \multicolumn{2}{|c|}{ Normalization } & \multirow{2}{*}{$\begin{array}{c}\text { Service Capability } \\
\text { Max Payload } \\
\text { Capability } \times \text { No-Load } \\
\text { Voyage }\end{array}$} \\
\hline & $\begin{array}{c}\text { Max Payload } \\
\text { Capability (lbs.) }\end{array}$ & $\begin{array}{r}\text { Speed } \\
(\mathrm{km} / \mathrm{h})\end{array}$ & $\begin{array}{c}\text { Flight Time No } \\
\text { Cargo (min) }\end{array}$ & $\begin{array}{c}\text { Ideal } \\
\text { Voyage }(\mathbf{k m})\end{array}$ & $\begin{array}{l}\text { Max Payload } \\
\text { Capability }\end{array}$ & $\begin{array}{l}\text { No-Load } \\
\text { Voyage }\end{array}$ & \\
\hline $\mathrm{A}$ & 3.5 & 40 & 35 & 23.33 & 0 & 0.22 & 0 \\
\hline $\mathrm{B}$ & 8 & 79 & 40 & 52.66 & 0.24 & 0.99 & 0.243 \\
\hline $\mathrm{C}$ & 14 & 64 & 35 & 37.33 & 0.57 & 0.59 & 0.337 \\
\hline $\mathrm{D}$ & 11 & 60 & 18 & 18 & 0.40 & 0.08 & 0.032 \\
\hline $\mathrm{E}$ & 15 & 60 & 15 & 15 & 0.62 & 0 & 0 \\
\hline $\mathrm{F}$ & 22 & 79 & 24 & 31.6 & 1 & 0.44 & 0.441 \\
\hline G & 20 & 64 & 16 & 17.06 & 0.89 & 0.054 & 0.049 \\
\hline H Tethered & $\mathrm{N} / \mathrm{A}$ & $\mathrm{N} / \mathrm{A}$ & Indefinite & $\mathrm{N} / \mathrm{A}$ & $\mathrm{N} / \mathrm{A}$ & $\mathrm{N} / \mathrm{A}$ & $\mathrm{N} / \mathrm{A}$ \\
\hline
\end{tabular}
and $z$ is the service capability.

Table 2. The results of normalization.

\subsection{Demand for Drugs}

In order to facilitate transportation, various drugs urgently needed in the disaster area were allocated into three medical packages (the size of each medical package is shown in Table 3). At the same time, various drugs required in the disaster area were displayed in the form of medical packages.

Table 3. Emergency Medical Package Configuration.

\begin{tabular}{ccc}
\hline Package ID & Weight (lbs.) & $\begin{array}{c}\text { Package Dimensions (in.) } \\
(\mathbf{L} \times \mathbf{W} \times \mathbf{H})\end{array}$ \\
\hline MED 1 & 2 & $14 \times 7 \times 5$ \\
MED 2 & 2 & $5 \times 8 \times 5$ \\
MED 3 & 3 & $12 \times 7 \times 4$ \\
\hline
\end{tabular}

According to the corresponding data, the quantity and demand of various drugs per day could be calculated.

The formula is as follows:

Volume:

$$
V_{P i}=L \times W \times H,
$$

where $V_{p i}$ is the volume of each medical box.

Medical demand:

$$
G_{i}=\sum_{j=1}^{5} M_{i j},(i=1,2,3),
$$

where $G_{i}$ is the demand of each medical box, and $M_{i j}$ is the demand of a medical box in a region. 


\subsection{Packing Problem of Container}

The International Standards Organization (ISO) standard dry cargo containers will be used to quickly transport a complete UAV disaster response system to a particular disaster area.

In order to minimize unused space per ISO container, the need for buffer material was minimized. The following models are established:

$$
\begin{aligned}
& \min V_{b}=V_{0}-V_{s}-V_{c}-V_{m} \\
& \text { s.t. }\left\{\begin{array}{c}
V_{s}=\sum_{i=A}^{H} V_{s i},(i=A, \cdots, H) \\
V_{c}=\sum_{i=1}^{2} V_{c i},(i=1,2) \\
V_{m}=\sum_{i=1}^{3}\left(G_{i} \times V_{P i}\right) \times t_{m},(i=1,2,3)
\end{array}\right.
\end{aligned}
$$

Among them, $V_{b}$ is the volume of the buffer material, $V_{0}$ is the volume of the ISO container, $V_{s}$ is the volume of the unmanned aerial vehicle, $V_{c}$ is the volume the unmanned aerial vehicle holds, and $V_{m}$ is the volume of all medical packs.

Standard ISO container dimensions are shown in Table 4. The packaging dimensions of the UAV hold are shown in Table 5.

Table 4. Standard ISO Container Dimensions.

\begin{tabular}{ccccccccc}
\hline & \multicolumn{3}{c}{ Exterior } & & \multicolumn{3}{c}{ Interior } & \multicolumn{3}{c}{ Door Opening } \\
\cline { 2 - 9 } & Length & Width & Height & Length & Width & Height & Width & Height \\
\hline $\begin{array}{c}20^{\prime} \text { Standard } \\
\text { Dry Container }\end{array}$ & $20^{\prime}$ & $8^{\prime}$ & $8^{\prime} 6^{\prime \prime}$ & $19^{\prime} 3^{\prime \prime}$ & $7^{\prime} 8^{\prime \prime}$ & $7^{\prime} 10^{\prime \prime}$ & $7^{\prime} 8^{\prime \prime}$ & $7^{\prime} 5^{\prime \prime}$ \\
\hline
\end{tabular}

Table 5. Drone Cargo Bay Packing Configuration/Dimensions by Type.

\begin{tabular}{ccccc}
\hline Drone Cargo Bay Type & Length (in) & Width (in) & Height (in) & \\
\hline 1 & 8 & 10 & 14 & Top Loaded \\
2 & 24 & 20 & 20 & Top Loaded \\
\hline
\end{tabular}

The total volume and space utilization rate of UAVs, UAV cargo bays, medical packages were calculated for the ISO cargo container; the formula is:

$$
V=V_{s}+V_{c}+V_{m}
$$

where $V$ is the total volume of items in ISO containers.

\subsection{Establishment of Traffic Planning Model}

To meet different demands, three traffic planning models with different objectives were established.

\subsubsection{Transportation Planning Model Based on Benefit Maximization}

According to the maximum rescue distance of the UAV disaster response system, the locations should be determined to follow the following four principles:

(1) Each delivery location was within at least one ISO cargo container of the UAV disaster response system's maximum rescue distance.

When $u_{i j}=1$, otherwise $u_{i j}=0$.

$$
\sum_{j=1}^{3} u_{i j} \geq 1,(i=1,2,3,4,5) .
$$


Among them,

$u_{i j}=1$ : Delivery Location can get help from location $j$.

$u_{i j}=0$ : Delivery Location cannot get help from location $j$.

(2) As many delivery points as possible could be handled by each ISO container of the UAV disaster response system.

$$
\max \sum_{i=1}^{5} u_{i j},(j=1,2,3)
$$

(3) Adjacent ISO cargo containers' distance was smaller than the maximum flight distance of the UAV.

$$
u_{j}=1,(j=1,2,3) \text {. }
$$

Among them,

$u_{j}=1$ : Adjacent ISO cargo containers' distance is smaller than the flight distance of the UAV.

$u_{j}=0$ : Adjacent ISO cargo containers' distance is not less than the flight distance of the UAV.

(4) The maximum number of roads could be detected in the maximum range.

$$
\max \sum_{k} \widetilde{u}_{j k},(j=1,2,3) .
$$

Among them,

$\tilde{u}_{j k}=1$ : location. $j$ can detect road $\mathrm{k}$.

$\tilde{u}_{j k}=0$ : location. $j$ can't detect road $\mathrm{k}$.

The best location to determine is on the coast.

After giving the objective function and constraint conditions, the multi-objective programming model with the maximum detection road and the maximum rescue capability as the objective function could be obtained:

$$
\begin{aligned}
& \max \sum_{i=1}^{5} u_{i j},(j=1,2,3) \\
& \max \sum_{k}^{k} \widetilde{u}_{j k},(j=1,2,3) \\
& \text { s.t. }\left\{\begin{array}{l}
\sum_{j=1}^{3} u_{i j} \geq 1,(i=1,2,3,4,5) \\
u_{j}=1,(j=1,2,3)
\end{array}\right.
\end{aligned}
$$

\subsubsection{Transportation Planning Model Based on Shortest Time}

To meet the emergency medical package identified, a single objective planning model with the shortest time was developed to pursue timeliness in rescue. Firstly, the shortest path was determined and, secondly, the UAV with a higher speed was selected first while satisfying the transportation requirements.

(1) Determine the shortest path to transport medical packages;

(2) Choose UAV.

Number the UAV of the UAV disaster response system, $q_{i j}$ represents No. $i \mathrm{UAV} q$ at location $j$.

Let the distance from location to Delivery location be $s$,

$$
\begin{gathered}
s=R \times \arccos \left[\left(x_{1}-x_{2}\right) \cos y_{1} \cos y_{2}+\sin y_{1} \sin y_{2}\right] \\
t=\frac{s}{v}
\end{gathered}
$$

$R=6370 \mathrm{~km}$ (Radius of the earth). 
Therefore, the single-objective programming model is as follows:

$$
\begin{aligned}
& \text { mint }=\frac{s}{v} \\
& \text { s.t. }\left\{\begin{array}{l}
s=R \times \arccos \left[\left(x_{1}-x\right) \cos y_{1} \cos y_{2}+\sin y_{1} \sin y_{2}\right] \\
W_{m i} \leq W_{q i} \\
s_{i j} \leq s_{0 i j} \\
v_{m i} \leq v_{c i}
\end{array}\right.
\end{aligned}
$$

\subsubsection{Traffic Planning Model Based on Maximum Road Coverage}

Road assessment requires that the UAV obtains accurate data when flying along the road, so it cannot be solved by a straight line distance. In order to extend the investigation time, multiple unmanned aerial vehicles were used to complete the investigation within the maximum extent using a piece wise detection method.

The road was divided into $n$ sections; one section of the road was detected by the first $\mathrm{UAV}$, and the second section was detected by the second $\mathrm{UAV}$, and $n$ is the same. Therefore, the road was completed by $n \mathrm{UAVs}$. The $n \mathrm{UAVs}$ could be investigated at the same time, or they could be investigated in turn. The location of the segmentation point needed to be selected in order to ensure that the distance the UAVs can fly was less than its maximum flight distance.

$$
l_{i}+k_{j} \leq s_{m} .
$$

The location of the rescue system needed to consider the distance from the coast, the distance to the drug demand point and other factors. The specific calculation formula is as follows:

$$
\begin{gathered}
d=R \times \arccos \left[\left(x_{1}-x_{2}\right) \cos y_{1} \cos y_{2}+\sin y_{1} \sin y_{2}\right] \\
\text { mind }<s_{m}
\end{gathered} .
$$

\subsection{Model Analysis}

There were some problems with the initial model. The above models were optimized during the validation process, and the validation results of the above models were better.

\section{Results and Analysis}

In order to verify the accuracy of the model, select the corresponding location in a certain area as the drug demand location. The specific location information of the demand

\begin{tabular}{|c|c|c|c|c|c|}
\hline \multicolumn{3}{|c|}{ Delivery Location } & \multicolumn{3}{|c|}{ Emergency Medical Packages ** } \\
\hline Location Name & Latitude & Longitude & Requirement & Quantity & Frequency \\
\hline \multirow{2}{*}{ Caribbean Medical Center, Fajardo } & \multirow{2}{*}{18.33} & \multirow{2}{*}{-65.65} & MED 1 & 1 & Daily \\
\hline & & & MED 3 & 1 & Daily \\
\hline \multirow{2}{*}{ Hospital HIMA, San Pablo } & \multirow{2}{*}{18.22} & \multirow{2}{*}{-66.03} & MED 1 & 2 & Daily \\
\hline & & & MED 3 & 1 & Daily \\
\hline \multirow{2}{*}{ Hospital Pavia Santurce, San Juan } & \multirow{2}{*}{18.44} & \multirow{2}{*}{-66.07} & MED 1 & 1 & Daily \\
\hline & & & MED 2 & 1 & Daily \\
\hline \multirow{3}{*}{$\begin{array}{l}\text { Puerto Rico Children's Hospital, } \\
\text { Bayamon }\end{array}$} & \multirow{3}{*}{18.40} & \multirow{3}{*}{-66.16} & MED 1 & 2 & Daily \\
\hline & & & MED 2 & 1 & Daily \\
\hline & & & MED 3 & 2 & Daily \\
\hline Hospital Pavia Arecibo, Arecibo & 18.47 & -66.73 & MED 1 & 1 & Daily \\
\hline
\end{tabular}
location and the quantity of drugs required are shown in Table 6. The exact location distribution is shown in Figure 1.

Table 6. Anticipated Medical Package Demand.

Note: Longitude, positive East longitude (+) and negative West longitude (-). Latitude, Positive North latitude (+) and negative South latitude (-). 


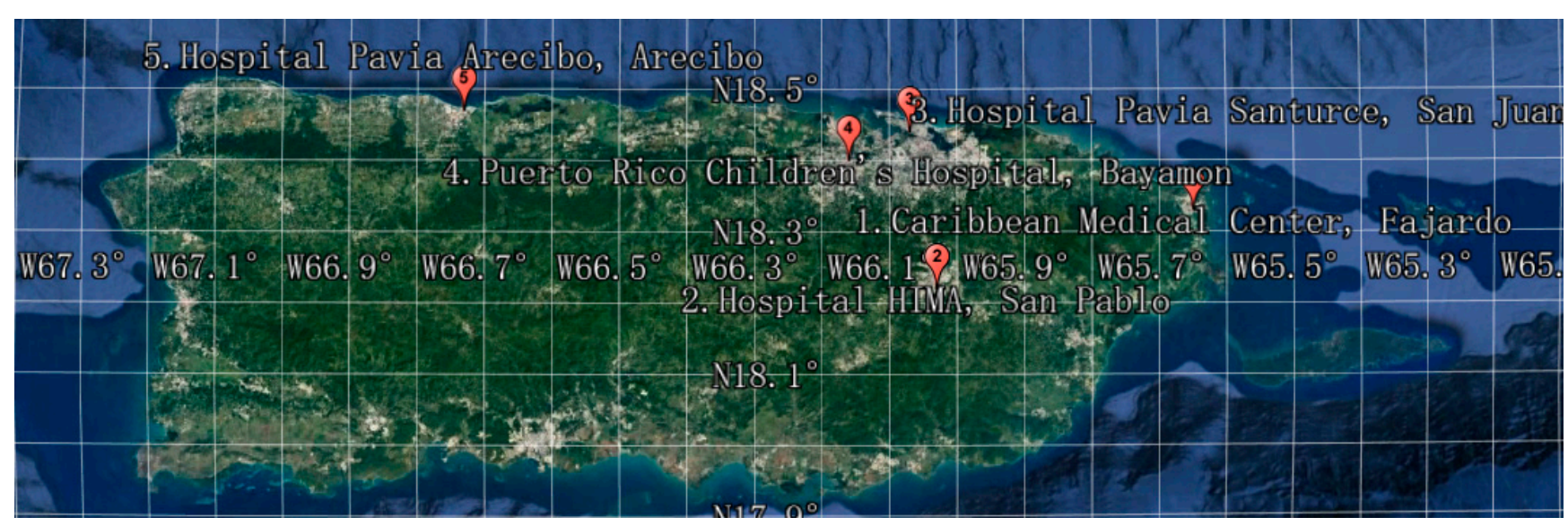

Figure 1. Location distribution map (WGS 48, ESPG:4326).

\subsection{UAV and Medical Package Allocation Results}

From MATLAB programming, it could be concluded that an ISO freight container could meet the 188-day rescue requirements. The hurricane lasted about 100 days from September 20 to December 31 in 2017 and had a lasting impact. Therefore, one ISO cargo container can meet this rescue need. If the rescue time is longer than 188 days, or the range is increased, then two or three ISO cargo containers should be considered to use. A UAV fleet and a set of medical packages for each ISO cargo container is shown in Table 7.

Table 7. ISO container assembly results.

\begin{tabular}{cccccccc}
\hline & \multicolumn{3}{c}{ UAV } & \multicolumn{3}{c}{ Medical Packages } \\
\hline \multirow{2}{*}{ Quantity } & B & C & F & H & MED1 & MED2 & MED3 \\
& 5 & 1 & 1 & 1 & 1316 & 376 & 752 \\
\hline
\end{tabular}

We can get $V=142637$, which satisfies $V<V_{i}$, and the space utilization rate is $71.4 \%$. Therefore, the model is reasonable.

\subsection{Solution of Traffic Planning Model Based on Maximization of Benefits}

\subsubsection{Place of Placement}

Through calculating, the need of three locations was determined, and were named $H$, $\mathrm{M}$ and P. For the specific positions of $\mathrm{M}$ and $\mathrm{P}$ in the overlapping region, it was considered to cover the road with the most coverage while meeting the requirements of the medical package transportation, so as to carry out video detection in a larger scope and to maximize its reliability. It stayed as far away from the boundary of the maximum rescue area as possible. Therefore, the middle of the coincidence region was selected. The positions of $H$, $\mathrm{M}$ and $\mathrm{P}$ are shown in Table 8.

Table 8. The geographical position of Locations.

\begin{tabular}{ccc}
\hline Location Name & Latitude & Longitude \\
\hline H & 18.43 & -66.10 \\
M & 18.48 & -66.54 \\
P & 18.43 & -65.85 \\
\hline
\end{tabular}

Note: Longitude, positive East longitude (+) and negative West longitude (-). Latitude, Positive North latitude $(+)$ and negative South latitude (-).

\subsubsection{Relative Distribution of Delivery Place and Location}

The geographical Location distribution of five delivery locations and three locations is shown in the map, as shown in Figure 2: The area enclosed by the solid line represents the farthest area reached by each Delivery Location round trip. The area enclosed by the dotted 
line represents the farthest that each Location round trip can reach. The area enclosed by the imaginary line represents the farthest that each Location, one-way can reach.

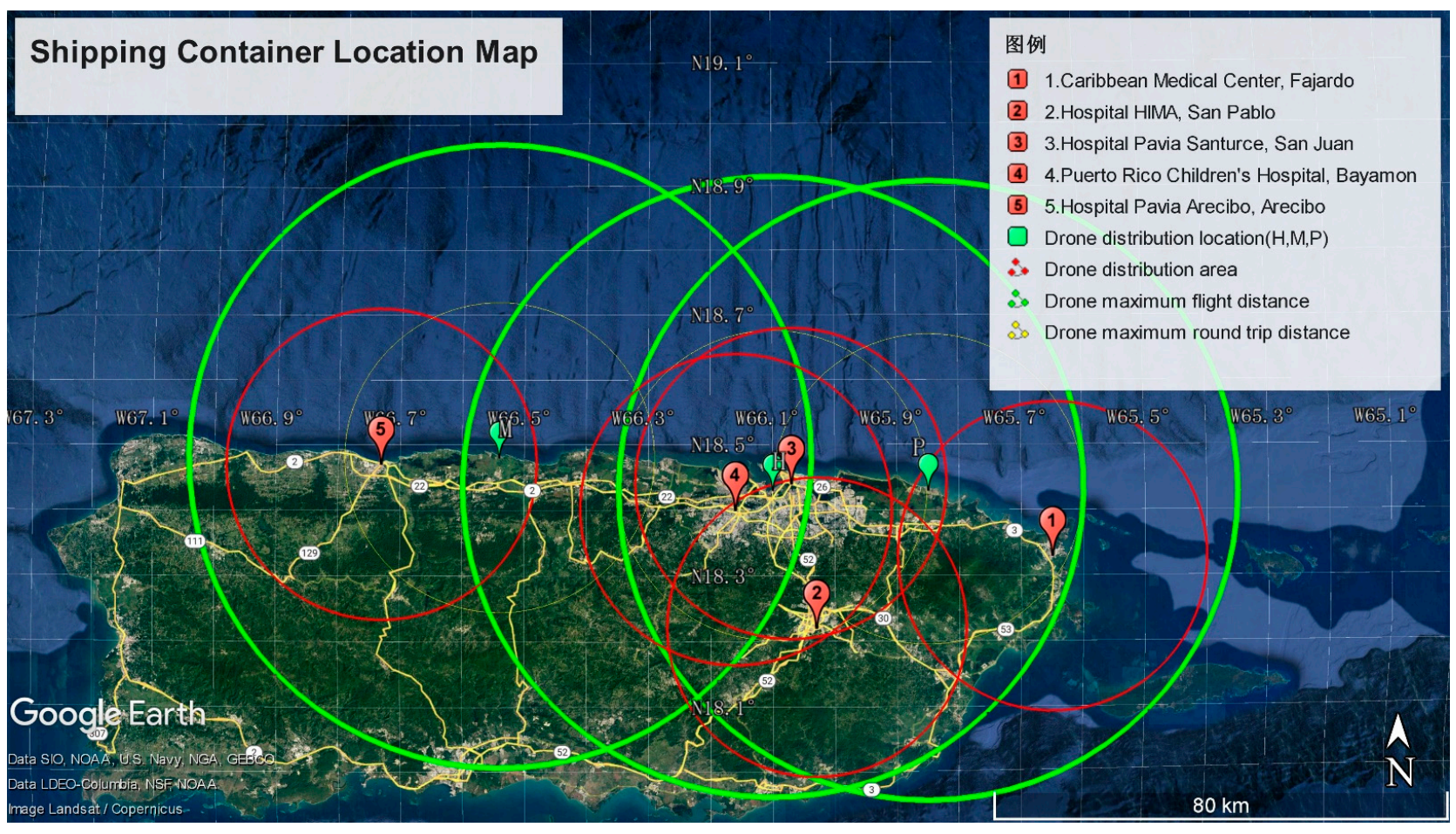

Figure 2. Location map (WGS 48, ESPG:4326).

It is obvious from observing Figure 2 that each Delivery Location was in at least the farthest area that could be reached by a round-trip to one Location. Therefore, medical packages could be delivered to all five Delivery Locations, and a lot of roads could be covered, with one-way coverage of $87.45 \%$ and round-trip coverage of $42.33 \%$. Therefore, the model is reasonable.

\subsubsection{Solution of Traffic Planning Model Based on Shortest Time}

The results obtained through calculation are shown in Table 9:

Table 9. The calculation of traffic planning model based on shortest time.

\begin{tabular}{ccccc}
\hline UAV & Payload b Packing Configurations & Delivery Routes & Distances (km) & Schedule (min) \\
\hline BP1 & 1MED1,1MED3 & P to CMC & 23.88 & 18.14 \\
BH2 & 1MED1,1MED3 & H to HS & 24.52 & 18.62 \\
BH3 & 1 MED1 & H to HPS & 3.36 & 2.55 \\
BH4 & 1MED1,1MED2 & H to RC & 7.16 & 5.44 \\
FH1 & 2MED1,1MED2 and 2 MED3 & M to PA & 20.1 & 15.26 \\
BM5 & 1 MED1 &
\end{tabular}

(Among them, CMC stands for Caribbean Medical Center; HHS is on behalf of HIMA Hospital San Pablo; HPS represents Hospital Pavia Santurce, PRC is on behalf of Puerto Rico Children's Hospital; (HPA rep. Hospital Pavia Arecibo.).

According to the analyzed calculation results, among the five delivery locations, the longest delivery time was the HIMA San Pablo Hospital, which takes 18.62 min, meeting the timeliness requirement of rescue. By comparing the results with the data given in the question, it could be seen that the weight of the medical packages installed by each UAV was less than its max payload capability and the flight distance was less than its flight distance, which meets the transport requirements. Therefore, this model is reasonable. 


\subsubsection{Solution of Traffic Planning Model Based on Maximum Road Coverage}

In this paper, the main road is selected for calculation in order to illustrate. Based on the depth-first search algorithm and the travel agent problem, it is solved by MATLAB programming. Figure 3 presents the algorithm flow chart.

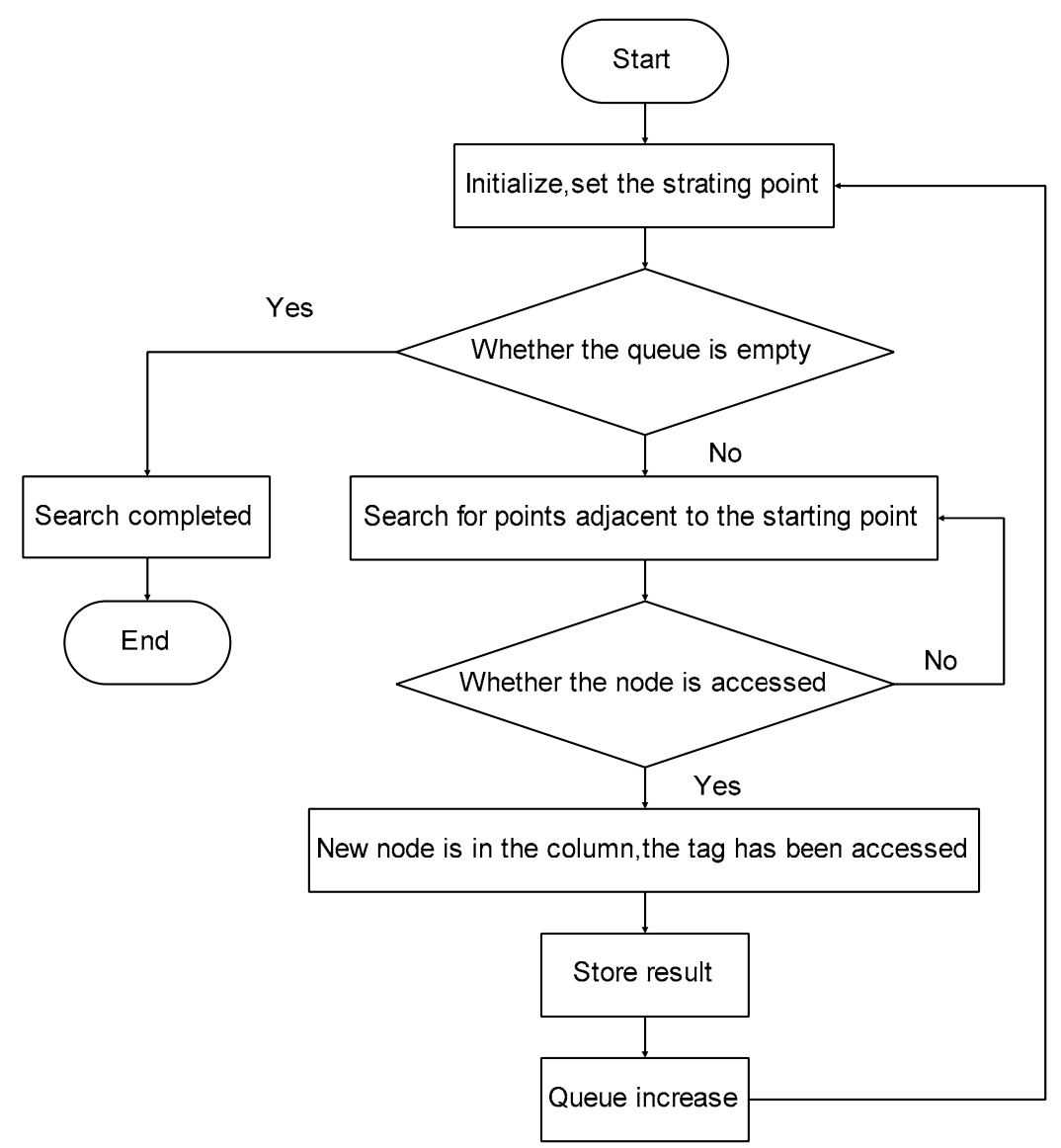

Figure 3. Algorithm flow chart.

Because of its limited navigation, an unmanned aerial vehicle sometimes cannot fully survey a road. It will mark a road that has been surveyed, starting at the end of the last survey. Figure 4 shows a diagram of a survey road.

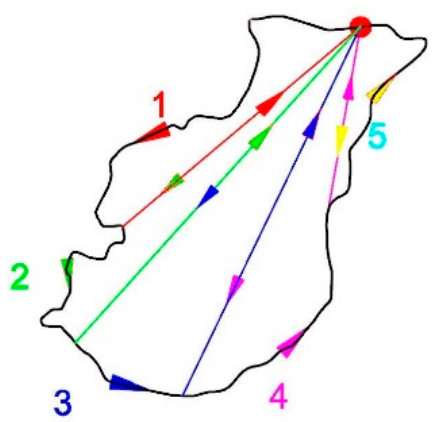

Figure 4. Road exploration diagram.

In the range of location $\mathrm{H}$, the length of the detection route is $164.9 \mathrm{~km}$; in the range of location $\mathrm{M}$, the length of the detection route is $168.97 \mathrm{~km}$. In the range of location $\mathrm{P}$, the length of the detection route is $159.11 \mathrm{~km}$. Figure 5 shows the flight path of one of the roads detected by the UAVs. 


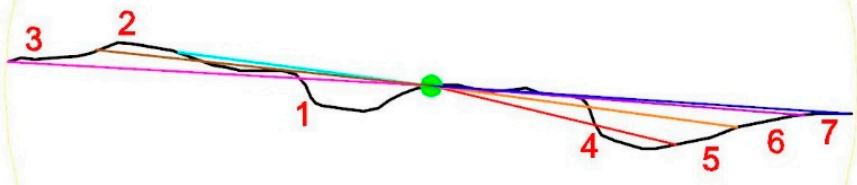

Figure 5. Investigation routes.

\subsection{Applicability of the Model}

In the process of model validation, the model can be applied to a variety of disasters (such as earthquakes, tsunamis, debris flows, etc.) and environments (such as islands, bays, and other coastal areas). This model has high applicability.

\section{Discussion}

Under the continuous impact of disasters, non-chronic patients were gradually transferred to hospitals and temporary shelters, resulting in a growing demand for health care. Even though the disaster response system has a strong generalizability and a flexible deployment capability, there are still some potential emergencies that need to be considered. For different practical situations, some discussions were made.

\subsection{Remote Destinations}

For delivery locations that are outside the maximum range for UAVs (but still within the one-way maximum range, as shown in Figure 6), equipped with UAV B (the longest distance and fastest flight speed in containers) and UAV F (the best carrying capacity), the appropriate types and quantities are allocated based on actual distances and required doses. In this case, the UAV flies in one direction to the destination and then recovers uniformly when conditions are appropriate.

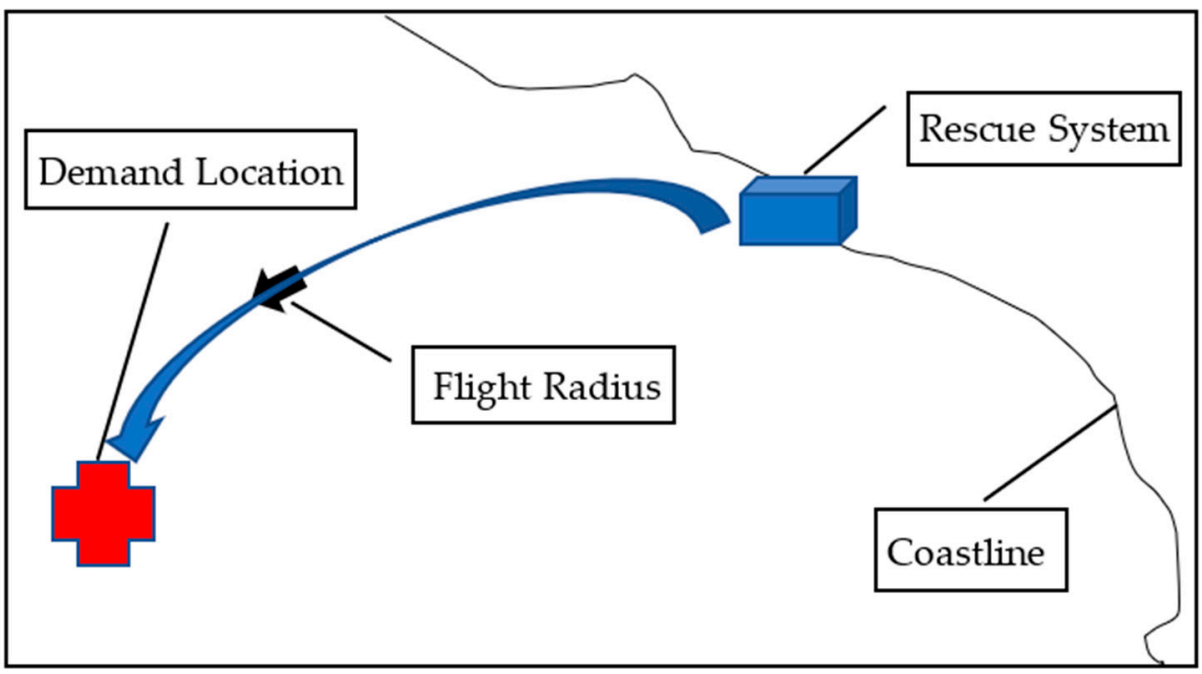

Figure 6. Overrun UAV radius diagram.

\subsection{There Are Too Many New Places}

In view of more new medical needs in one area, the deployment of UAVs between containers is considered when setting container locations, and the distance between containers is controlled as far as possible to match the antennae of some UAVs. In addition, there are standby unmanned aerial vehicles in the container. When a situation occurs, an appropriate 
number of unmanned aerial vehicles can be quickly mobilized from adjacent containers to meet the needs of emergency multi-location transportation. If adjacent containers are still unable to meet demand, further unmanned aerial vehicles can be placed in the containers.

In this case, it is also possible to set up a transfer station in a single location in a denser but less demanding location, using large capacity UAV F and UAV B to form fleets, with UAV B to transport between the transfer station and the destination, in order to improve transportation efficiency and reduce the number of flights.

\subsection{There Is Too Much Demand for Medicine}

When a large number of urgent needs are concentrated in a certain area or when the disaster impact time is long, some container medicine may be insufficient or the distribution of container medicine to various places may be uneven. In this case, due to the flexibility between containers, medicines can be transported from other containers to their respective destinations through appropriate unmanned aerial vehicles.

The disaster response system designed in this paper can still respond to the urgent needs of different situations by enabling flexible deployment between the standby machine and each container beyond the actual working capacity. These characteristics give us enough confidence to face more unknown disaster situations.

\section{Conclusions}

In order to reasonably configure the emergency response system, the corresponding model of a UAV is selected according to the actual situation, and is equipped with the appropriate number of drugs, and a three-dimensional packing model is established to form a single ISO response unit. In order to improve transportation efficiency, three models - a transportation planning model based on benefit maximization, a transportation planning model based on shortest time and a traffic planning model based on maximum road coverage-were established, which are applicable to different situations respectively. Through the simulation of specific areas, the results are ideal. Through repeated debugging of the model, models suitable for island and continental coastal areas are formed.

Compared with other rescue methods, the UAV rescue system has the advantages of fast response, strong adaptability and wide rescue scope. It is suitable for disaster relief in coastal areas and island areas. It can effectively reduce the losses caused by disasters, improve the survival rate of people in the affected areas, and provide a reference for future research on disaster relief and mitigation.

Author Contributions: Conceptualization, H.Z. (Huibin Zhu) and H.Z. (Haoran Zhao); Data curation, H.Z. (Haoran Zhao); Methodology, W.Y.; Software, H.Z. (Haoran Zhao); Validation, H.Z. (Huibin Zhu), H.Z. (Haoran Zhao) and W.Y.; Writing-original draft, H.Z. (Haoran Zhao); Writing-review \& editing, H.Z. (Huibin Zhu) and W.Y. All authors have read and agreed to the published version of the manuscript.

Funding: This research was funded by the National Natural Science Foundation of China, grant number 51865022.

Institutional Review Board Statement: Not applicable.

Informed Consent Statement: Not applicable.

Data Availability Statement: The data used to support the findings of this study are available from the corresponding author upon reasonable request.

Acknowledgments: This work is supported by the National Natural Science Foundation of China (Grant NO. 51865022).

Conflicts of Interest: The authors declare no conflict of interest. 


\section{References}

1. Kishore, N.; Marques, D.; Mahmud, A.; Kiang, M.W.; Rodriguez, I.; Fuller, A.; Ebner, P.; Sorensen, C.; Racy, F.; Lemery, J.; et al. Mortality in Puerto Rico after Hurricane Maria. N. Engl. J. Med. 2018, 379, 162-170. [CrossRef]

2. Satake, K.; Okal, E.A.; Borrero, J.C. Tsunami and its Hazard in the Indian and Pacific Oceans: Introduction. Pure Appl. Geophys. 2007, 164, 249-259. [CrossRef]

3. Mavroulis, S.; Lekkas, E. Revisiting the Most Destructive Earthquake Sequence in the Recent History of Greece: Environmental Effects Induced by the 9, 11 and 12 August 1953 Ionian Sea Earthquakes. Appl. Sci. 2021, 11, 8429. [CrossRef]

4. Simons, M.; Minson, S.E.A.S.; Ortega, F.; Jiang, J.; Owen, S.E.L.M.; Ampuero, J.-P.; Wei, S.; Chu, R.; Helmberger, D.V.; Kanamori, H.; et al. The 2011 Magnitude 9.0 Tohoku-Oki Earthquake: Mosaicking the Megathrust from Seconds to Centuries. Science 2011, 332, 1421-1425. [CrossRef]

5. Mavroulis, S.; Triantafyllou, I.; Karavias, A.; Gogou, M.; Katsetsiadou, K.-N.; Lekkas, E.; Papadoupoulos, G.A.; Parchardis, I. Primary and Secondary Environmental Effects Triggered by the 30 October 2020, Mw = 7.0, Samos (Eastern Aegean Sea, Greece) Earthquake Based on Post-Event Field Surveys and InSAR Analysis. Appl. Sci. 2021, 11, 3281. [CrossRef]

6. Najafi, J.; Peiravi, A.; Guerrero, J.M. Power distribution system improvement planning under hurricanes based on a new resilience index. Sustain. Cities Soc. 2018, 39, 592-604. [CrossRef]

7. An, C. Tsunamis and tsunami warning: Recent progress and future prospects. Sci. China Earth Sci. 2020, 64, 191-204. [CrossRef]

8. Song, M.-J.; Cho, Y.-S. Modeling Maximum Tsunami Heights Using Bayesian Neural Networks. Atmosphere 2020, 11, 1266. [CrossRef]

9. Gusman, A.R.; Tanioka, Y.; Macinnes, B.T.; Tsushima, H. A methodology for near-field tsunami inundation forecasting: Application to the 2011 Tohoku tsunami. J. Geophys. Res. Solid Earth 2014, 119, 8186-8206. [CrossRef]

10. Alizadeh, R.; Nishi, T.; Bagherinejad, J.; Bashiri, M. Multi-Period Maximal Covering Location Problem with Capacitated Facilities and Modules for Natural Disaster Relief Services. Appl. Sci. 2021, 11, 397. [CrossRef]

11. Janik, P.; Zawistowski, M.; Fellner, R.; Zawistowski, G. Unmanned Aircraft Systems Risk Assessment Based on SORA for First Responders and Disaster Management. Appl. Sci. 2021, 11, 5364. [CrossRef]

12. Duran, S.; Gutierrez, M.A.; Keskinocak, P. Pre-Positioning of Emergency Items for CARE International. Interfaces 2011, 41, 223-237. [CrossRef]

13. Velasquez, G.A.; Mayorga, M.E.; Özaltin, O.Y. Prepositioning disaster relief supplies using robust optimization. IISE Trans. 2020, 52, 1122-1140. [CrossRef]

14. Ozdamar, L. Planning helicopter logistics in disaster relief. OR Spectr. 2011, 33, 655-672. [CrossRef]

15. Okuno, Y.; Kobayashi, K.; Ishii, H. Development of a Helicopter Operations Management System for Disaster Relief Missions. J. Am. Helicopter Soc. 2016, 61, 1-9. [CrossRef]

16. Deng, H.; Xin, G.; Zhong, G.; Mistry, M. Gait and trajectory rolling planning and control of hexapod robots for disaster rescue applications. Robot. Auton. Syst. 2017, 95, 13-24. [CrossRef]

17. Tuna, G.; Nefzi, B.; Conte, G. Unmanned aerial vehicle-aided communications system for disaster recovery. J. Netw. Comput. Appl. 2014, 41, 27-36. [CrossRef]

18. Villaseñor, C.; Gallegos, A.A.; Lopez-Gonzalez, G.; Gomez-Avila, J.; Barragan-Hernandez, J.; Daniel-Arana, N. Ellipsoidal Path Planning for Unmanned Aerial Vehicles. Appl. Sci. 2021, 11, 7997. [CrossRef]

19. Goodrich, M.A.; Morse, B.S.; Gerhardt, D.; Cooper, J.L.; Quigley, M.; Adams, J.A.; Humphrey, C. Supporting wilderness search and rescue using a camera-equipped mini UAV. J. Field Robot. 2008, 25, 89-110. [CrossRef]

20. Zhou, Y.; Cheng, N.; Lu, N.; Shen, X.-S. Multi-UAV-Aided Networks: Aerial-Ground Cooperative Vehicular Networking Architecture. IEEE Veh. Technol. Mag. 2015, 10, 36-44. [CrossRef]

21. Giordan, D.; Adams, M.S.; Aicardi, I.; Alicandro, M.; Allasia, P.; Baldo, M.; De Beradinis, P.; Dominici, D.; Godone, D.; Hobbs, P.; et al. The use of unmanned aerial vehicles (UAVs) for engineering geology applications. Bull. Eng. Geol. Environ. 2020, 79, 3437-3481. [CrossRef]

22. Casella, E.; Drechsel, J.; Winter, C.; Benninghoff, M.; Rovere, A. Accuracy of sand beach topography surveying by drones and photogrammetry. Geo-Mar. Lett. 2020, 40, 255-268. [CrossRef]

23. Alzenad, M.; El-Keyi, A.; Lagum, F.; Xia, X.-G. 3-D Placement of an Unmanned Aerial Vehicle Base Station (UAV-BS) for Energy-Efficient Maximal Coverage. IEEE Wirel. Commun. Lett. 2017, 6, 434-437. [CrossRef]

24. Kou, G.; Lin, C.S. A cosine maximization method for the priority vector derivation in AHP. Eur. J. Oper. Res. 2014, 235, $225-232$. [CrossRef] 